\title{
El hombre ante los «mass-media»
}

Citando a Georges Friedmann, el sociólogo Jean Schwöbel ${ }^{1}$ reconoce que los medios de comunicación social son capaces de garantizar la divulgación de la información auténticamente veraz y necesaria; de estimular la curiosidad inteligente y el interés legítimo por los nuevos temas, situaciones y problemas; de ampliar los horizontes del saber humano; de desarrollar el gusto artístico y las virtudes morales. Pero también advierte que son capaces de degradar, de pervertir y de esclavizar a la persona humana no sólo en los países atrasados por el totalitarismo político-ideológico o por la miseria económica y cultural, sino también en los ambientes generalmente orgullosos de su vivencia de las libertades democráticas. Tanto a los individuos como a las masas - es un hecho patente - se les puede manipular sicológicamente para que acepten el desorden, vivan una vida vacía y moral, apoyen una dictadura, compren un producto que no necesitan o se acostumbren a unos hábitos superfluos, inútiles o dañosos. De esta manera los medios de comunicación social pueden hacer un servicio inapreciable al hombre y a la sociedad o pueden provocar las más hondas crisis y fomentar las más retrógradas confusiones. Todo depende de su punto de partida que - si no es un lamentable equívoco, un error involuntario o una grave irresponsabilidad - quiere uno de estos dos aspectos: la presunción o la esperanza.

Entre estas dos concepciones y estilos se ha producido, a veces, no sólo una profunda crisis de pensamiento, de conducta ciudadana y de posturas sociales, sino también una gran parte del confusionismo actual. Sería ingenuo cerrar los ojos ante las supuestas causas de la crisis ética en la que se encuentra sumergido el hombre hoy. Muchos ven estas causas en el hecho de que la ética y la moral "tradicional» tienen una única dimensión, la exterior, mientras el hombre actual desea afirmarse a sí mismo desde su propio interior y de una manera autónoma y personal. Hoy el hombre está sometido a las condiciones -condicionamientos- exteriores: circunstancias sociales, económicas, culturales, políticas... Lo que antes quedaba reservado a unos pocos es absorbido 
ahora en la vida de una multitud. El hombre recibe lo que ocurre en otros ambientes y puntos de vista diferentes sobre la vida. Todos pueden seguir la discusión de temas candentes de actualidad.

Es necesario que los sociólogos, juristas, pedagogos, economistas, sicólogos, teólogos, etc... traten en profundidad, como lo hacen, desde su punto de vista, el fenómeno de la comunicación de masas, ya que entra de lleno en todas esas áreas de estudio. Pero sus aportaciones, por muy importantes que sean, constituyen tan sólo un estudio parcial del fenómeno de la comunicación como tal, puesto que, como materia científica, es posible explicarla por sus propias causas materiales, formales y eficientes. Sin duda alguna necesita la ilustración y la iluminación desde diversos ángulos, aunque sin ello seguirá existiendo y será lo que es.

Tanto la praxis profesional como el estudio científico de la comunicación de masas se proyectan directa o indirectamente en la vida de las personas, de las comunidades y de toda la sociedad. Masificado o no, el hombre se deja guiar o arrastrar por los medios de comunicación social y, como reacción, intenta recompensarse buscando la libertad en el terreno ético y moral, acotado, en buena parte, en el refugio de la vida interior. Eso quiere decir que el que trabaja en los medios debe tener claros y seguros los principios éticos. No sólo por su propio bien, sino también, en la misma medida por el bien de los demás. Ahí reside su responsabilidad de la que no se debe desprender mientras pretenda ser fiel a su vocación y a su labor profesional.

El hombre contemporáneo se encuentra en un mundo en pleno desarrollo científico y tecnológico que proporciona nuevas y, frecuentemente, inesperadas dimensiones al saber y a la creatividad humana. Estamos presenciando una pujante evolución científica que se manifiesta en la rapidez y en la amplitud de la aplicación de los descubrimientos científicos en los procesos tanto programáticos como productivos. Así como antes desde el descubrimiento científico hasta su aplicación pasaban varios decenios, hoy los resultados de la investigación se aplican inmediatamente a la práctica. Esta aceleración es posible, en primer lugar, porque los propios investigadores suelen dirigir la puesta en práctica de sus descubrimientos al campo de la productividad industrial, o de la difusión mediante la docencia. El hombre hoy se siente como perdido sin la cantidad abundante y sin la diversidad amplia de datos informativos referentes a todos los sectores de la creatividad y la actividad humanas. Para conseguir esta abundancia informativa el hombre tiene a su disposición métodos y técnicas que le facilitan y proporcionan todo lo que quiere saber. Sin embargo, precisamente en la divulgación y difusión periodística se dan casos en los que esta cantidad y diversidad no se refieren tanto a la riqueza informativa, sino más bien a distintos aspectos e interpretaciones de unos mismos hechos, acontecimientos y tendencias que, a veces son tan pobres como las propias corrientes en boga que obsesionan a los informadores poco responsables. Generalmente el problema no consiste en la escasez de noticias, consideradas estas en números absolutos, sino en el hecho de que una parte de los 
medios informativos enfoca tendenciosamente las noticias, buscando a toda costa el «gancho» fácil, el impacto barato y el sensacionalismo ruidoso

Claudicar ante esta invasión de procedimientos, mal llamados periodísticos, no sería una solución al problema, sino un intento de detener el tiempo en algún momento de la historia, más o menos reciente, o en algún rincón de las intenciones injustas que -como decía Charles Péguy- no son injustas casualmente, sino intrínsecamente ${ }^{2}$. Con ello no quiero decir que, pese a todo, haya que aceptar lo que se nos ofrece como información (aunque tenga todos los aspectos de deformación), sino que una posible actitud pasiva ante tales intenciones, significaría dejar el campo libre a un periodismo presuntuoso y amoral. De esta manera se participaría con la propia pasividad en el origen de nuestra claudicación. Este problema es de vital importancia para la sociedad en que vivimos, ya que «el triunfo de las demagogias por breve que sea, provoca ruinas que pueden ser eternas» ${ }^{3}$. Los medios de comunicación de masas deberían proporcionar a los receptores, por lo menos, la posibilidad de juzgar por sí mismos los hechos y los acontecimientos actuales de diversos signos y contenidos, expresando no unas verdades torcidas y adulteradas, sino unas realidades dignas de ser registradas, comentadas y tratadas con la mayor objetividad posible. Hoy en día, cuando se habla tanto de los derechos de la persona humana, hace falta recordar que uno de los fundamentales puntos de estos derechos es, sin duda, la seguridad de que el público sea informado veraz y correctamente.

Es lógico que el hombre contemporáneo no masificado se encuentre en cierto sentido preocupado. El mundo que le rodea se ha hecho más complicado y el hombre común, metido en los estrechos marcos de su vida rutinaria, se deja arrastrar con frecuencia por la fuerza de los acontecimientos y de las ideas complejas, ininteligibles o, sencillamente, de moda que, en el fondo, no comprende en absoluto o no comprende bastante y que, precisamente por ello, le dejan la sensación de que vive un destino inevitable del que no se puede librar ni adueñar. Se produce así una de las más significativas paradojas del fenómeno informativo: la mayor cantidad de información debería, lógicamente, enriquecer el saber del hombre, desarrollar su sentido democrático y fomentar más su libertad. Pero, en general, ocurre precisamente lo contrario. El hombre contemporáneo se encuentra envuelto en una multitud de informaciones de todo tipo, hasta tal punto que ni las selecciona ni puede hacerlo consciente y reflexivamente, porque carece de la capacidad y la preparación suficiente o no dispone del tiempo necesario. Esta realidad se agrava cuando los medios de comunicación social seleccionan la información (los programas radiofónicos y televisivos, los textos publicados son, en realidad, una forma de selección, puesto que no comunican toda la información disponible) sin cri-

2. Charles Peguy: Clio, Gallimard, París, 1917.

3. İbid. 
168

. Dí Z TORTAJADA

n $\mathrm{i}$

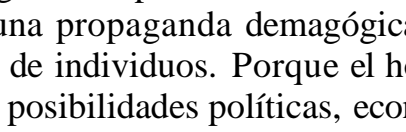

d

$\mathrm{u}$

$\mathrm{t}$

je

a

t

$\mathrm{p}$

$\mathbf{P}$

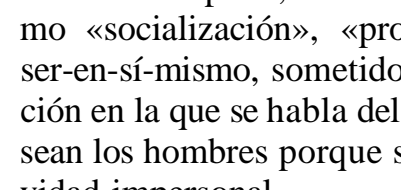

e rí

b

.. $\mathrm{h}$

z

-

L

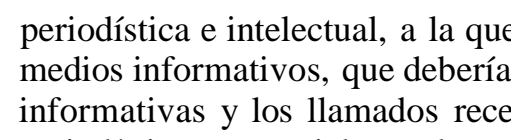

$\begin{array}{llll}\mathrm{Q} & & & \\ \mathrm{g} & & \mathrm{a}\end{array}$

de $\mathrm{m} \quad \mathrm{i}$

mí icas par co $\mathbf{v}$

$\mathrm{r}$
$\mathrm{y}^{\mathrm{l}} \mathrm{C}$

$\mathrm{x}^{\mathrm{C}}$

r

s ó .

m

a

f

q

n $\begin{array}{llll}\text { e } P & E^{\prime} & u\end{array}$

$\mathbf{X}$

b

a $o$

4

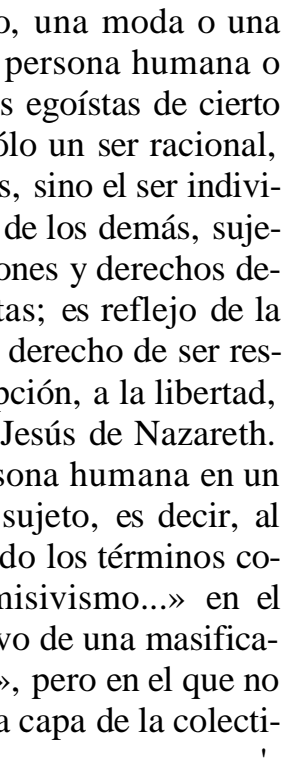

y

$\mathrm{p}$

ó eg

i

d

c

d

b

m

Ex

r.

g

$\mathrm{fu}$

a

i

d

a p p

e

o

$\begin{array}{ccc} & \text { h } & \text { a- } \\ \text { a } & \text { ye } & \\ \text { e } & \text { u }\end{array}$ 
ro. Sin embargo, las posibilidades que aparecen ahora ante nosotros no llevan necesariamente hacia su realización. Cualquier creación humana, de cualquier modelo de conocimientos, supone la limitación que reside en la diversidad de los elementos que componen el conjunto de lo que tenemos o queremos conocer. Todo conocimiento, y por lo tanto también el conocimiento logrado gracias a los medios de comunicación, representa un proceso que presupone la diferenciación de los detalles y la elección de los elementos necesarios para la creación del modelo de conocimiento del que se trata. De allí surgen las diferencias obligatorias entre la amplitud de la variedad de la realidad objetiva y la cantidad de la subjetividad de aquel que informa. El aspecto de la realidad objetiva es teóricamente más abundante que el aspecto reflejado por el sujeto. La capacidad de reducir múltiples elementos y el volumen de variedades expresivas, incluye la inevitable condición de la abstracción, que hace posible el conocimiento de los aspectos esenciales de un fenómeno librado del amontonamiento de elementos sin importancia o imprevistos. Porque únicamente de este modo se puede penetrar en la médula de las cosas y problemas y llegar hasta la definición exacta de las nociones y de los hechos. Estos principios generales del conocimiento son muy importantes en el proceso de creación del sistema de expresión libre que constituye uno de los aspectos más esenciales de los contenidos periodísticos informativos ${ }^{4}$. Sin una cuidadosa diferenciación y sin una elección consciente y responsable de los elementos informativos puede llegarse, y de hecho se llega, a la deformación, a la imagen errónea de las situaciones y del mundo ${ }^{5}$. De esta manera, la perspectiva de aquellas posi-

4. JORGE XIFRA HERAS: Las fuerzas políticas en su acción sobre la información, (Conferencia). Curso de Ciencias de la Información, Palacio de la Magdalena, Santander, julio 1974. He aquí nuestro esquema de expresión y recepción del mensaje informativo:

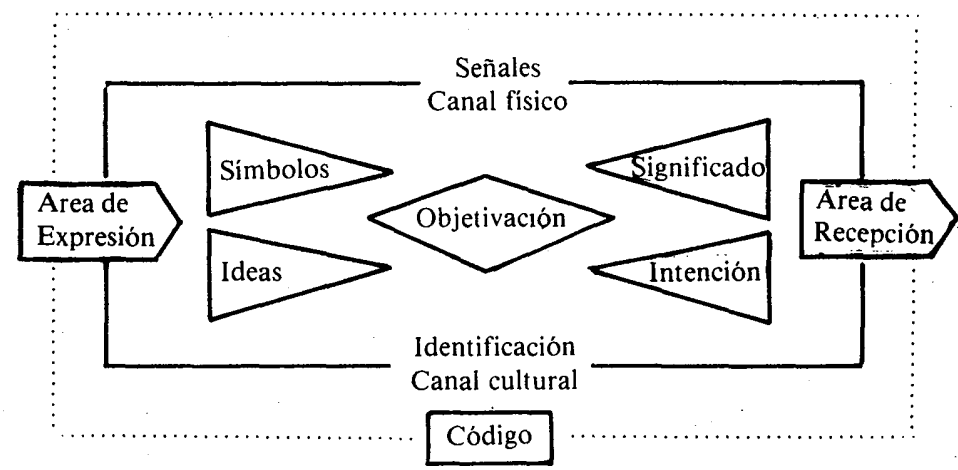

5. Schramm: Factor de selectividad, Esquema del proceso de la comunicación, CiEsPal, Quito (Ecuador), 1967.

Factor de selectividad $=$

Esperanza de recompensa

Esfuerzo necesario 
bilidades reales, características de un verdadero progreso se convierte en una muralla tras la que desaparecen los horizontes. No basta sólo el saber, si en él no cabe la constante mirada hacia el fin último del hombre que, como tal, incluye la libertad de los hijos de Dios y la servidumbre del genio humano a toda la humanidad. Lo que la técnica y la ciencia aporta como unas fuentes de la felicidad humana - si el placer, los egoísmos, la hipocresía y la comodidad son entendidos como tal felicidad- pueden, también, convertirse en su propia perdición. Así, el hombre de hoy que más bien intuye la perspectiva de una alternativa entre el progreso y la destrucción, empieza a entrever el enorme peligro que comporta su incapacidad de participar en las actividades reservadas a unos pocos. Y cuando se habla de la información periodística estos «unos pocos» son en primer lugar los informadores - redactores, colaboradores, corresponsables...-, los medios informativos y las empresas.

El hombre, pese a su inseguridad y a su desconcierto provocado por las actuales crisis, no es un ser pasivo, dispuesto a permitir que le deslicen hacia unos fines desconocidos, configurados borrosamente en el conjunto de la complejidad del mundo. La idea de su propia dignidad le salva de un fatalismo vacío, hueco y falto de contenido y le impone la conciencia sobre la necesidad de buscar y encontrar soluciones para la alternativa ante la cual se encuentra la existencia del ser humano. Se convence de que el desarrollo social, proporcionado por los avances tecnológicos y científicos, no se realiza espontánea o automáticamente como consecuencia de los cambios económicos, políticos o culturales. Es cada vez más patente la comprensión de que su futuro depende de los factores humanos, es decir, de los valores intelectuales, morales y religiosos que controlan y disciplinan los valores infrahumanos y subculturales, fomentados no sólo por sus inclinaciones instintivas, sino también por las informaciones, programas, publicaciones y obras envueltas en ropajes artísticos, dañosas, mediocres o falsas. El hombre que se aprecia como tal ni desea ni puede vivir un largo período la vida del «hombre parcial y casual». Antes o después rechaza el ahogarse en el ritmo de lo superficial y perverso. Desea librarse de las cadenas de una información tendenciosa, porque se da cuenta de su vocación de hombre en la sociedad. Desea romper los límites de un supuesto mundo concreto que le rodea y que le mutila, cuando no le falsifica por completo. También desea salvarse del crepúsculo verpertino de la llamada verdad y objetividad informativa, en la que la praxis individual y comunitaria se convierte en rutina, en la que el hombre se siente extraño a sí mismo y a su verdadera condición de persona humana. Tiende a ser el hombre completo y no se contenta con el destino de naufragar en la masificación colectiva que, a veces, se prepara y fomenta en los centros informativos escépticos, tendenciosos o absorbidos por los rugidos ideológicos y las corrientes voceadoras. El hombre consciente de sí mismo, de sus deberes y obligaciones, de sus derechos y libertad... de su dignidad humana, busca el camino para librarse de las condiciones raquíticas en las que se desenvuelve su propia existencia para llegar a su plenitud personal. Así llega a la convicción de que puede de- 
sarrollar no sólo su quehacer dinámico, sino también su destino trascendente.

Pese a todas las confusiones y a los climas socio-políticos inciertos, el hombre busca y crea medios que hacen posible satisfacer su deseo de actuar con responsabilidad ante la historia y de participar activa y creativamente en la problemática actual. Los medios de comunicación social son precisamente uno de los conductores de inapreciable valor que pueden y deben ayudarle en ese camino de la integración del hombre común en la vida social. En teoría, estos medios sirven como conductos para conocer el mundo contemporáneo y para participar en la creación de lo que mañana será la historia. Pero si estos medios proporcionan noticias, datos e ideas que sólo están en concordancia con unas propagandas demagógicas de tal o cual signo o, simplemente, con la inmoralidad, entonces también esta participación en la creación presente va a resultar deformada y falseada, dando tal o cual sentido a toda nuestra época. Naturalmente, no se puede hablar así en términos absolutos, porque también nuestro presente cuenta con sectores humanos responsables que amortiguan el efecto de esta tónica generalizada del mundo actual. No obstante, sería cerrar los ojos ante la realidad el no reconocer que precisamente en una buena medida «Los medios de comunicación invaden hoy con estrepitosa facilidad la opinión pública y confieren a hechos mínimos unos efectos desorbitados» 6 . La verdad es que los medios informativos no sólo cuentan y comentan los sucesos interesantes sino que también influyen sobre el desarrollo de los acontecimientos y, mucho más, sobre el presente vivido por las multitudes, ambientes sociales y comunidades.

Uno de los mayores obstáculos para la labor constructiva de la información periodística es la actual definición negativa de la noticia que tan ad litteram se aplica al quehacer diario redaccional. A base de esta definición las tragedias, las catástrofes, las crisis, los escándalos, son noticias de la primera página en algunos periódicos, mientras que los esfuerzos de un país o una comunidad por salvarse de sus dificultades o los logros en el campo artístico, cultural, económico... tienen una prioridad muy baja y se pueden encontrar en las páginas que se leen poco o que tan sólo se ojean.

Lo más importante de la labor informativa es enriquecer los valores intelectuales y morales del receptor por medio de la información; cosa posible presentando una preciosa oportunidad de participar mucho más intensa y extensamente en la historia a los amplios sectores de la sociedad. Esto, naturalmente, excluye no sólo el periodismo Schund (palabra alemana que significa escoria, desperdicio, residuo inútil y hasta dañoso), sino también el periodismo pasivo que se limita únicamente a registrar los acontecimientos, porque esta manera de informar es opuesta tanto a un periodismo consciente de sus deberes profesionales, como la propia objetividad que se suele destacar como su

6. Pablo vi: Discurso del día 2 de diciembre de 1969: L’Osservatore Romano, 3 de diciembre de 1969. 
defensa. Tal información verdaderamente imparcial, esencialmente ambigua y lo ambiguo nunca puede ser objetivo ni verdadero. Precisamente por ello, la información tendenciosa y la carente de fisonomía intrínseca suelen ser como una antítesis enmascarada de la información correcta, divulgando, junto con las verdades, los errores y las mentiras. En este sentido la labor periodística cuando no es maliciosa es mediocre, sin criterios o con unos criterios erróneos referentes a la propia información como tal.

Dejando a un lado el periodismo presuntuoso y rutinario se debe destacar con la mayor fuerza la existencia y la necesidad de un periodismo de la esperanza que procura evitar escollos y los precipicios.

Sin duda el periodista no puede saber todo, comentar en breves plazos la totalidad de lo que se le presenta, orientar a los receptores en todos los casos. Actualmente los sectores de la vida social son tan complejos que el periodismo necesita de especialistas que dominen los temas propuestos y el lenguaje propio de los medios informativos que utilizan. Pero siempre ha de darse la alegría de la búsqueda de la verdad, el descubrimiento de nuevas perspectivas y de nuevas luces que proporcionen a la vida mayor seguridad y más atractivo. El periodista debe encender la luz allí donde reina la oscuridad, la luz de la verdad que, en cuanto haya llegado a iluminar muchas mentes, no se puede apagar ni impedir que extienda su acción en el alma del que la ha recibido. Pero para conseguirlo hacen falta dos condiciones: ejercer el periodismo activamente y tener una recta visión del mundo por parte del informador.

La labor informativa no puede ser reducida a un simple registro de los acontecimientos o a la simple divulgación de las noticias producidas, sino que debe estar centrada en una permanente atención a la dinámica de los valores políticos, sociales, culturales, morales, científicos, religiosos... valores que proporcionan las mejores soluciones a los dilemas impuestos por las circunstancias y el progreso de nuestro tiempo. Hace falta un periodismo que sea algo más que la historia de un día.

No basta, pues, talento y vocación. Se trata de formar hombres que tienen en sus manos esa «arma terrible» capaz de cambiar los ambientes, la sociedad y el mundo. Y para que este cambio no sea desastroso, hace falta que esa arma la tengan los hombres que sepan emplearla para el bien, para la paz, para la prosperidad y para la verdadera libertad de los hombres.

Junto a la gran confusión de nuestro presente y el hervir ideológico parece sentirse a cada paso que todas formas de vida pública han envejecido ý que todos los fundamentos se tambalean. Existe la sensación de que el presente pertenece al pasado y que ha de llegar algo completamente distinto. Esta sensación sólo parcialmente es una esperanza. Más bien es la rutina cotidiana de la vida que corre sin cesar y vuelve también constantemente. Las preocupaciones y las noticias diarias se remozan igualmente en las páginas abiertas de buenas intenciones, en los ensueños realizados o en las desilusiones del hombre, como en los periódicos y revistas que leemos o en los programas que vemos y oímos. Este tipo de vida prosaica, que es de uno y que es de todos, co- 
mún y vulgarizadora, toda esta historia pasajera que es siempre núeva y siempre semejante a sí misma, resume para muchos todo el destino del hombre, cuando éste carece de altura, de perspectivas más amplias de lo que puede ofrecer el tiempo.

Este es el «material» que maneja y configura el periodista, consciente o no de que la libertad de la información tiene un doble aspecto: la libertad de recibir y emitir las ideas, las noticias, y el derecho a una información veraz y completa, ya que el derecho a la información es la consecuencia necesaria de la libertad informativa ?

La información es como es el que informa. $Y$ el informador no puede ser ni un autómata, ni un oportunista sin escrúpulos, ni un escéptico. La noticia, el dato está ahí, como se produce. La información no es algo que aparece por sí solo. Siempre hay alguien que informa y su enfoque no es necesariamente una falsificación del hecho, aunque sí lo será si se trata de una falsedad, calumnia, suposiciones gratuitas y no justificadas, o de un camuflaje oportunista. El enfoque en concordancia con úna visión del mundo honrada sana y limpia no es más que el tratamiento legítimo de la información ${ }^{8}$.

«Aparte de la vida interna de la Iglesia - decía Pablo VI a profesionales de la información- vosotros sois testigos también de nuestras preocupaciones por todo lo que afecta la existencia de nuestros contemporáneos los derechos del hombre, la familia, la cultura, los problemas económicos y sociales, la construcción de la comunidad internacional. Es cierto, no hay sector humano que no atraiga nuestra solicitud. La constitución Gaudium et spes nos muestra el secreto de nuestro interés, de nuestra solidaridad con las esperanzas y angustias de los hombres de nuestro tiempo. En todos estos sectores, tienen los cristianos un servicio que realizar con todos los demás hombres, sin perder de vista la realización del reino de los cielos. Se comprometen con la urgencia de la caridad. Nuestra visión puede pareceros muy optimista: y lo es, ciertamente. Estamos seguros de que Dios ha salvado al mundo y ha prometido a los hombres su Espíritu. ¡Ojalá vosotros hagáis resonar ampliamente nuestra esperanza! Los hombres tienen necesidad de ella para emprender la construcción de un mundo mejor. Un acto de amor generoso es un acontecimiento más importante que un acto de odio" ${ }^{9}$.

\section{Antonio Díaz TORTAJADA.}

7. J. Boürouin: La liberté de la presse, Presse Universitaire de France, París, 1950, págs. 65 y ss. Fernard Terrou y L. Solal: Derecho a la informacion, Unesco, París, 1957.

8. «Los medios de comunicación social tienden a simplificar los problemas por dos razones fundamentales. Las limitaciones de tiempo y espacio hacen difícil y costoso el tratar por extenso los asuntos... La complejidad y el refinamiento intelectual darian por resultado eliminar grandes sectores del auditorio popular» (Th. M. GARRET: Manipulación y medios de comunicación. Concilium, 65 (1971), pág. 221.

9. Pablo vi, Discurso a un grupo de periodistas el 23 de enero de 1973: L'Osservatore Romano, 24 de enero de 1973. 